\section{Is Granuloma Annulare a Seasonal Dermatosis}

Granuloma Annulare (GA) is a chronic granulomatous disorder of unknown etiology. Local forms of GA tend to occur on sunexposed extremities, and variants of GA induced by sun exposure or localized to sun-damaged skin have been described [1-4]. Similarly, disseminated forms of GA that relapse following sun exposure are known, although drug induced variants including vaccinal and interstitial GA have been described [4]. Actinic granuloma of O'Brien, which is closely related to GA and considered to be a form of GA by some experts, also occurs exclusively on sun-damaged skin [5].

In order to determine if there is a seasonal pattern to GA appearance, a retrospective analysis of histopathological and clinical reports was done at the Ackerman Academy of Dermatopathology. Using the computer database, we included 753 total cases diagnosed at the Ackerman Academy from 2008-2011. Specimens were obtained

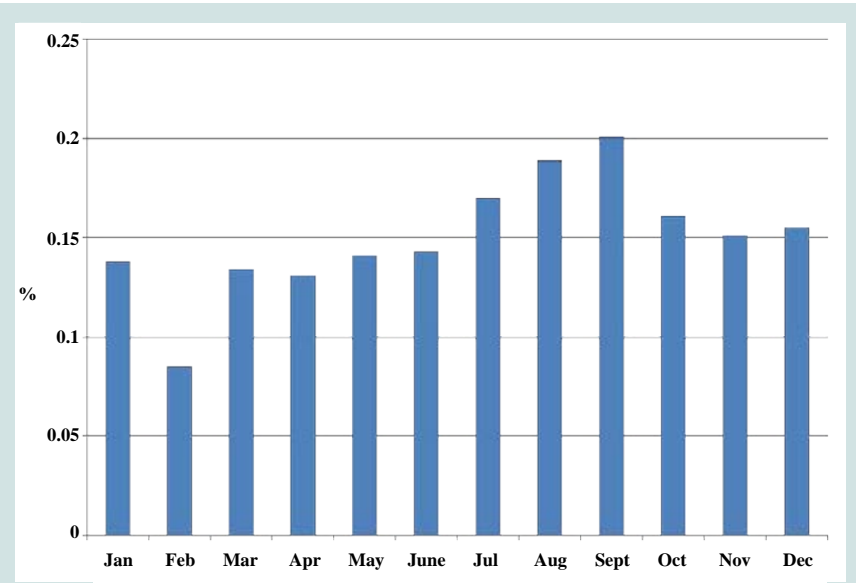

Figure 1: Average percentage of cases of granuloma annulare diagnosed by month during the period $2008-2011$.

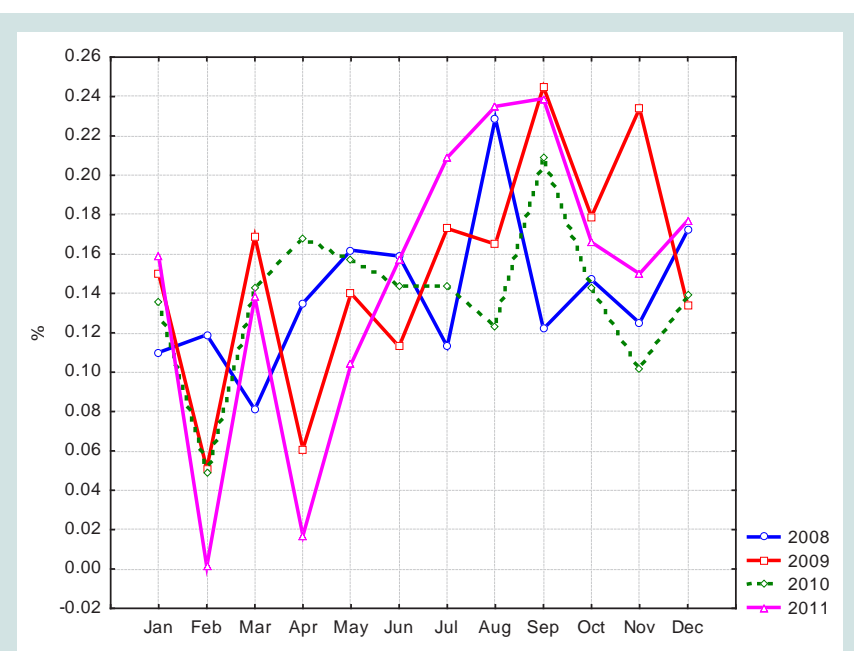

Figure 2: Percentage of cases of granuloma annulare diagnosed by month each year during the period $2008-2011$.

\section{Journal of}

Clinical \& Investigative Dermatology

\author{
Saurabh Malhotra ${ }^{1}$, Viktoryia Kazlouskaya ${ }^{2 *}$, Collin \\ Blattner $^{3}$ and Dirk Elston ${ }^{2}$ \\ ${ }^{1}$ Department of Pathology, Dartmouth-Hitchcock Medical Center, \\ Lebanon, $\mathrm{NH}$ \\ ${ }^{2}$ Ackerman Academy of Dermatopathology, New York, USA \\ ${ }^{3}$ Des Moines University, Iowa, USA \\ *Address for Correspondence \\ Viktoryia Kazlouskaya, Ackerman Academy of Dermatopathology, 145 \\ East 32nd Street, $10^{\text {th }}$ floor, New York, USA, Tel: 8005536621; E-mail: \\ viktoriakozlovskaya@yahoo.com \\ Submission: 02 December 2013 \\ Accepted: 21 December 2013 \\ Published: 26 December 2013 \\ Reviewed \& Approved by: Dr. Kyoung-Chan Park, is a Professor \\ in Department of Dermatology at Seoul National University Bundang \\ Hospital, Korea
}

from 574 females and 179 males with an average age $53.7 \pm 16.7$ years. A total of 500,432 cases were signed out during the study period. The percentage of GA cases diagnosed in every month was calculated by taking into account the number of diagnosed cases during that month to exclude variation of specimen number throughout the year.

The number and percentage of biopsies of GA diagnosed in summer calendar months were statistically higher compared to those diagnosed during winter calendar months (221 and 142 cases respectively; $\mathrm{p}=0.01$ - Fisher exact test, Statistica $10^{\circ}$, Tulsa, OK). The average number and percentage of GA cases per month increased from March to September, with peaks seen in August and September. Subsequently, a steady decline in the number of GA biopsies was seen as winter progressed, with February having the fewest number of GA cases (Figure 1). When the cases were divided by year, peak incidence of GA was seen in August or September, although a steady increase throughout the summer months were not always seen (Figure 2).

While the date of the biopsy does not always correspond to the onset of the condition, patients are often prompted to seek treatment because of the appearance of new lesions or during exacerbations. Our data suggests that the incidence of GA is increased in the late summer and early falls months, but the data is limited since we are unable to pinpoint the primary onset of disease and or time of flare. Additionally, more people may seek treatment for a cosmetically troubling disease during warmer months because of increased opportunities for outdoor activity and ultraviolet sunlight exposure.

There is some evidence to support phototherapy including psoralen and ultraviolet A (PUVA) in the treatment of GA, with clearance or good improvement of generalized GA in $66 \%$ of cases [6]. However, prolonged remission occurred in less than a third of patients, which further obscures the pathogenicity of GA [6]. Consequently, we posit that one of the possible mechanisms of pathogenicity in sun-induced GA is an antigenic change to collagen or elastic fibers prompting phagocytosis. Numerous factors, including sun exposure in GA, may play a role in this phenomenon and should be further investigated. 
Citation: Malhotra S, Kazlouskaya V, Blattner C, Elston D. Is Granuloma Annulare a Seasonal Dermatosis. J Clin Investigat Dermatol. 2013;1(1): 2.

ISSN: 2373-1044

\section{References}

1. Leppard B, Black MM (1972) Disseminated granuloma annulare. A variant in which the lesions involve the sun-exposed areas. Trans St Johns Hosp Dermatol Soc 58: 186-190.

2. McLelland J, Young S, Marks JM, Lawrence CM (1991) Seasonally recurrent granuloma annulare of the elbows. Clin Exp Dermatol 16: 129-130.

3. Uenotsuchi T, Imayama S, Furue M (1999) Seasonally recurrent granuloma annulare on sun-exposed areas. $\mathrm{Br} J$ Dermatol 141: 367
4. Dabski K, Winkelmann RK (1989) Generalized granuloma annulare: clinical and laboratory findings in 100 patients. J Am Acad Dermatol 20: 39-47.

5. Ragaz A, Ackerman AB (1979) Is actinic granuloma a specific condition? Am J Dermatopathol 1: 43-50.

6. Browne F, Turner D, and Goulden V (2011) Psoralen and ultraviolet A in the treatment of granuloma annulare. Photodermatol Photoimmunol Photomed 27: 81-84

\section{Copyright}

(C) 2013 Malhotra S, et al. This is an open access article distributed under the Creative Commons Attribution License, which permits unrestricted use, distribution, and reproduction in any medium, provided the original work is properly cited. 